\title{
Quantitative and Qualitative Assessment of Pulmonary Emphysema with T2-Weighted PROPELLER MRI in a High-Risk Population Compared to Low-Dose CT
}

\section{Quantitative and qualitative Bewertung von Lungenemphysemen mit T2-gewichteter PROPELLER-MRT in einer Hochrisiko-Population verglichen mit Niedrigdosis-CT}

Authors

Michael Meier-Schroers, Alois Martin Sprinkart, Manuel Becker, Rami Homsi, Daniel Thomas

Affiliation

Radiology, University of Bonn, Germany

Key words

$\mathrm{CT}$, thorax, MR imaging

received 20.12.2017

accepted 02.02 .2018

Bibliography

DOI https://doi.org/10.1055/a-0577-5619

Published online: 7.3.2018

Fortschr Röntgenstr 2018; 190: 733-739

(C) Georg Thieme Verlag KG, Stuttgart · New York

ISSN 1438-9029

\section{Correspondence}

Dr. Michael Meier-Schroers

Radiologie, Universitatsklinikum Bonn,

Sigmund-Freud-Str. 25, 53127 Bonn, Germany

Tel.: ++ 49/2 28/28715960

Fax: ++ 49/2 28/28715598

mmeierschroers@gmail.com

\section{ZUSAMMENFASSUNG}

Ziel Evaluation der Eignung der T2-gewichteten PROPELLERMRT für die Bewertung von Lungenemphysemen.

Material und Methoden Es wurden 60 Teilnehmer eines Lungenkrebsscreenings (30 mit und 30 ohne Lungenemphysem) in diese retrospektive Studie eingeschlossen. Im Rahmen des Screenings wurden alle Studienpatienten mittels Niedrigdosis-CT (NDCT) und MRT untersucht. Für diese Studie wurde analysiert, ob eine T2-gewichtete PROPELLER-Sequenz für die Bewertung von Lungenemphysemen eingesetzt werden kann. Die Ergebnisse der MRT wurden mit denen der NDCT verglichen. Das Vorliegen und die Ausprägung eines Lungenemphysems wurden zunächst qualitativ mit einem 3-Punkte-Score bewertet. Danach wurden Emphysem-Indices mit Hilfe einer halbautomatischen Software quantitativ bestimmt.
Ergebnisse Das Vorliegen eines Lungenemphysems wurde in allen 30 Fällen korrekt von der MRT erkannt. Es gab 3 Fälle mit einem Emphysem laut MRT, die keine emphysematösen Veränderungen in der NDCT aufwiesen (falsch-positive Ergebnisse). Die Emphysem-Scores und die Emphysem-Indices waren sowohl in der NDCT als auch in der MRT signifikant höher in der Emphysemgruppe als in der Kontrollgruppe $(p<0,001)$. Es gab eine signifikante Korrelation der Scores und der Indices zwischen der MRT und der NDCT (Scores der Emphysemausprägung: $r=0,912 / p<0,001$ in der Emphysemgruppe und $r=0,668 / p<0,001$ in der Kontrollgruppe; Emphysemindices: $r=0,960 / p<0,001$ in der Emphysemgruppe und $r=0,746 / p<0,001$ in der Kontrollgruppe).

Schlussfolgerung Es ist denkbar, dass das Vorliegen und die Ausprägung von Lungenemphysemen qualitativ und quantitativ mittels T2-gewichteter PROPELLER-MRT bewertet werden können, mit sehr guten Korrelationen zur NDCT.

\section{Kernaussagen:}

- Die T2-gewichtete PROPELLER-MRT könnte sich für die Bewertung von Lungenemphysemen eignen.

- Es zeigten sich signifikante Korrelationen zwischen der MRT und der NDCT bezüglich der qualitativen Scores und bezüglich der quantitativen Emphysem-Indices in unserer Studie mit Korrelationskoeffizienten von $r=0,668$ bis $r=0,960$ bei verschiedenen Subgruppen.

- Die T2-gewichtete PROPELLER-MRT könnte sich für Verlaufskontrollen bei Patienten mit schwerwiegendem Emphysem eignen, um die Strahlenbelastung durch wiederholte CTs zu vermeiden.

\section{ABSTRACT}

Purpose To determine the suitability of T2-weighted PROPELLER MRI for the assessment of pulmonary emphysema.

Materials and Methods 60 participants in a lung cancer screening program (30 subjects with pulmonary emphysema, and 30 control subjects without emphysema) were included for this retrospective study. All subjects were examined with low-dose CT (LDCT) and MRI within the screening program. The use of a T2-weighted PROPELLER sequence for the assess- 
ment of emphysema was analyzed and correlated with the results of $L D C T$. The presence and the extent of pulmonary emphysema were first assessed qualitatively using a threepoint score, and then quantitatively with a semi-automated software program to obtain emphysema indices.

Results All 30 cases with pulmonary emphysema were accurately detected by MRI. There were 3 cases with emphysema according to MRI without emphysematous changes on LDCT (false-positive results). The qualitative scores as well as the emphysema indices were significantly higher in the emphysema group compared to the control group for MRI and LDCT $(p<0.001)$. Both the scores and the indices correlated significantly between MRI and LDCT (qualitative score of severity: $r=0.912 / p<0.001$ in the emphysema group and $r=0.668 /$ $p<0.001$ in the control group; emphysema index: $r=0.960 /$ $p<0.001$ in the emphysema group and $r=0.746 / p<0.001$ in the control group).

Conclusion The presence and the extent of pulmonary emphysema may be assessed qualitatively and quantitatively by T2-weighted PROPELLER MRI with very good correlation to LDCT.

\section{Key Points:}

- T2-weighted PROPELLER MRI may be suitable for the assessment of pulmonary emphysema.

- There was significant correlation between MRI and LDCT regarding qualitative scores and quantitative emphysema indices in our study with correlation coefficients for different subgroups ranging from $r=0.668$ to $r=0.960$.

- T2-weighted PROPELLER MRI may have the potential to be used for follow-up examinations in patients with severe emphysema to avoid radiation exposure of repeated CTs.

\section{Citation Format}

- Meier-Schroers M, Sprinkart AM, Becker M et al. Quantitative and Qualitative Assessment of Pulmonary Emphysema with T2-Weighted PROPELLER MRI in a High-Risk Population Compared to Low-Dose CT. Fortschr Röntgenstr 2018; 190: 733-739

\section{Introduction}

Pulmonary emphysema, as a common finding in long-term smokers and a leading cause of mortality worldwide, is characterized by irreversible destruction of the lung parenchyma [1, 2]. Computed tomography $(\mathrm{CT})$ plays an important role in the visualization and characterization of pulmonary emphysema, and it has previously been shown that $\mathrm{CT}$ findings can predict mortality in COPD [1, 3]. Moreover, the degree of emphysema on CT images can be quantified by computing low attenuation areas under a specific threshold [4-6].

Magnetic resonance imaging (MRI) allows for radiation-free lung imaging, but the low proton density of the lung parenchyma, susceptibility artifacts at air-tissue interfaces, and the vulnerability to respiratory and cardiovascular motion artifacts makes lung imaging with MRI still challenging [7 - 9].

Even though a decrease in lung density further complicates image acquisition, several studies have shown the feasibility of MRI for the assessment of pulmonary ventilation and emphysema. Most studies report on the use of ultrashort echo time (UTE) imaging, as well as functional MRI with Fourier decomposition or inhalation of hyperpolarized noble gases [10-17]. However, especially the latter approach is highly technically demanding.

Besides the aforementioned MRI techniques, it has been shown that conventional structural T2-weighted MRI using the Periodically Rotated Overlapping ParallEL Lines with Enhanced Reconstruction (PROPELLER) technique can depict pulmonary nodules and changes in lung tissue in general [18-21]. Hence, the aim of this study was to evaluate whether T2-weighted PROPELLER imaging might also be used for the assessment of pulmonary emphysema.

\section{Materials and methods}

\section{Study participants}

The study population consisted of 224 participants in a lung cancer screening study comparing low-dose CT (LDCT) and MRI. To be included for the screening, the participants had to be $50-70$ years old with a long history of cigarette smoking (at least 15 cigarettes per day for at least 25 years, or at least 10 cigarettes per day for at least 30 years). Study participants were active smokers or had quit for not more than 10 years. The screening study was approved by the institutional review board and by the federal agency for radiation protection. Written informed consent was obtained from all study subjects. For the present study, we retrospectively included 30 participants with pulmonary emphysema according to LDCT, and 30 participants without emphysema.

\section{Technique}

For this study, a transverse T2-weighted sequence using the PROPELLER technique (MultiVane XD, Philips Healthcare, Best, The Netherlands) as part of our MRI screening protocol was evaluated. The sequence was acquired on a clinical 1.5 Tesla scanner (Ingenia, Philips Healthcare, Best, The Netherlands) with an anterior phased-array body coil. The imaging parameters were as follows: repetition time $2200-2500 \mathrm{~ms}$, echo time $60 \mathrm{~ms}$, flip angle $90^{\circ}$, FOV $400 \mathrm{~mm}$, matrix $432 \times 432 \mathrm{~mm}$, slice thickness $6 \mathrm{~mm}$, acquisition time 3:18 min with respiratory gating. Other sequences of the MRI protocol were transverse T2-weighted STIR (short tau inversion recovery) MVXD, coronal T2-weighted MVXD, transverse balanced steady-state free precession, and coronal 3D T1-weighted gradient echo, yet these sequences were not evaluated for this present study. 
LDCT was performed on a clinical 128-slice spiral CT scanner (iCT, Philips Healthcare, Best, The Netherlands) in inspiratory breath-hold with a reconstructed slice thickness of $2 \mathrm{~mm}$. The tube current-time product was $25 \mathrm{mAs}$, the tube voltage was $120 \mathrm{kV}$ and the volume CT dose index was $1.8 \mathrm{mGy}$, leading to a dose length product of $70-90 \mathrm{mGy}^{*} \mathrm{~cm}$. All participants underwent LDCT and MRI within the same day or week.

\section{Image analysis}

LDCT images of 224 participants of our lung cancer screening program were retrospectively evaluated for the presence of pulmonary emphysema by a radiologist with 4.5 years of experience. The window settings of the LDCT datasets for this analysis were window width 1500 Hounsfield Units (HU) and window level - $700 \mathrm{HU}$. First, the presence and severity of emphysema were assessed qualitatively using a three-point scale: $0=$ no emphysema, 1 = moderate emphysema (centrilobular lucencies occupying approximately $>5 \%$ of a lung zone OR scattered small juxtapleural lucencies), 2 = severe emphysema (coalescent centrilobular and lobar lucencies including multiple regions OR multiple mainly large juxtapleural lucencies). Second, morphological patterns of emphysema were evaluated: 1 = predominantly centrilobular emphysema with scattered, multiple or coalescent centrilobular lucencies (few paraseptal lucencies may be present), 2 = predominantly paraseptal emphysema with scattered or multiple paraseptal lucencies (few centrilobular lucencies may be present), $3=$ mixed or advanced destructive emphysema. These definitions followed the statements of the Fleischner Society published in 2015 [4]. Third, automated emphysema analysis was performed using a commercially available software program (IntelliSpace Portal, Philips Healthcare, Best, The Netherlands) in order to obtain emphysema indices (EI).

Lung parenchyma was considered emphysematous when it showed attenuation values of below $-930 \mathrm{HU}$ at inspiration. An emphysema index (EI) was calculated for each LDCT dataset, defined as the percentage of lung volume with emphysema divided by the total lung volume. The presence of pulmonary emphysema was defined as an El of $\geq 6 \%$ or when multiple lucencies were clearly visible on LDCT. LDCT datasets in which extensive atelectasis and/or pulmonary infiltrates led to an opacification of approximately one third of a pulmonary lobe were excluded $(n=10)$. Subjects for which the automated analysis of LDCT images did not work appropriately due to noise overlay were also excluded $(n=27)$. This was seen in adipose individuals in particular. There are three reasons for the malfunction of the automated analysis: 1) Automated lung segmentation from trachea and surrounding tissue failed. 2) Quantitative results showed excessive emphysema indices that were apparently false positive. 3) Emphysema assessment included several parts of soft tissue and bones also leading to false-positive results.

This led to 30 subjects with pulmonary emphysema. 30 of the remaining 157 participants of our lung cancer screening program who did not show pulmonary emphysema were randomly selected as control subjects.

MR images of the 30 subjects with pulmonary emphysema according to the LDCT definition mentioned above (mean age:
$60.3 \pm 6.4$ years) were presented to two radiologists with 6.5 years and 16 years of experience, respectively, together with the 30 control subjects (mean age: $58.3 \pm 5.8$ years). The datasets were anonymized and presented in random order. The MR images were evaluated in consensus. Again, the presence of emphysema was first assessed qualitatively with predefined image windowing using the same three-point scales as for LDCT. Then, automated quantitative analysis was performed using a software program custom written in MATLAB (The MathWorks, Inc., Natick, Massachusetts, USA). With the help of this program, the lungs were segmented from soft tissue, bones and large vessels using a region growing algorithm with a threshold value of $<50 \%$ of the mean muscle signal obtained at 3 different positions across the imaging volume. Voxels erroneously classified as lung tissue (e. g. trachea) were manually removed from the lung segmentation. A second threshold value of $<15 \%$ of the muscle signal was used to define emphysematous lung parenchyma. Both thresholds followed the study of Roach et al. on the performance of ultrashort echo time (UTE) MRI for evaluating pulmonary emphysema [13], but were adjusted empirically to the T2-weighted sequence used in this present study corresponding well to the $-930 \mathrm{HU}$ selected for emphysema assessment on LDCT. The chosen MRI thresholds were determined by one author of the manuscript who was not taking part in qualitative and quantitative emphysema analysis to avoid a bias. The thresholds were chosen after investigating other different thresholds (e. g. $<70 \%$ for lung segmentation and $<10 \%$ for definition of emphysema).

\section{Statistical analysis}

Statistical analysis was performed with SPSS 24 (IBM, Armonk, New York, USA). Spearman coefficient was applied for correlation of qualitative scores between MRI and LDCT (presence/severity and morphological patterns). Pearson coefficient, linear regression analysis and Bland-Altman plot were applied for comparison of emphysema indices as calculated by MRI and LDCT. The MannWhitney U-Test was used to define differences of qualitative scores and emphysema indices between MRI and LDCT.

\section{Results}

All 30 cases with pulmonary emphysema according to low-dose CT (LDCT) were accurately detected by MRI. There were 3 subjects who seemed to have emphysema on MRI according to qualitative assessment, yet they did not show emphysematous changes on LDCT (false-positive results). One of these subjects showed multiple centrilobular lucencies and a slightly elevated emphysema index (EI) of $5.4 \%$ according to MRI, while the LDCT did not show emphysema and an El of $0.9 \%$. LDCT and corresponding MR images of this case are shown in $>$ Fig. 1. In the other two cases, quantitative measurement on MRI did not correspond to emphysema with indices of $2.7 \%$ and $2.1 \%$, respectively.

The mean qualitative emphysema score was significantly higher in the emphysema group compared to the control group for MRI (1.47 vs. $0.10, p<0.001)$ and for LDCT (1.50 vs. 0.0, $\mathrm{p}<0.001)$. The scores regarding severity and morphological patterns of emphysema correlated significantly between MRI and 


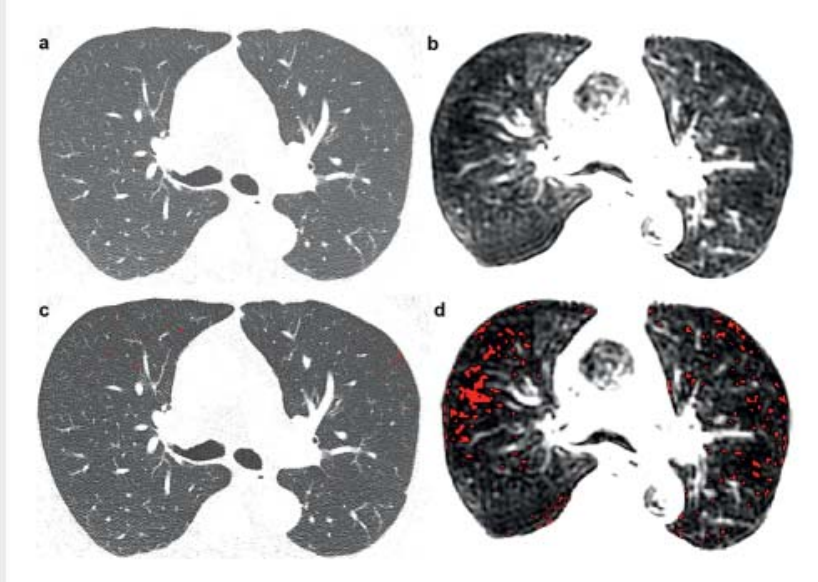

- Fig. 1 Qualitative and software-based quantitative assessment of pulmonary emphysema in a subject without emphysema according to CT (a, c; emphysema index of $0.9 \%$ ). This subject showed falsepositive signs of emphysema on MRI (b, d; centrilobular lucencies and emphysema index of $5.4 \%$ ).

- Abb. 1 Qualitative und software-basierte quantitative Emphysemanalyse bei einem Patienten ohne Emphysem in der CT (a, c; Emphysemindex von $0,9 \%$ ). Dieser Patient zeigte falsch-positive Zeichen eines Emphysem in der MRT (b, d; zentrilobuläre Aufhellungen und Emphysemindex von 5,4\%).

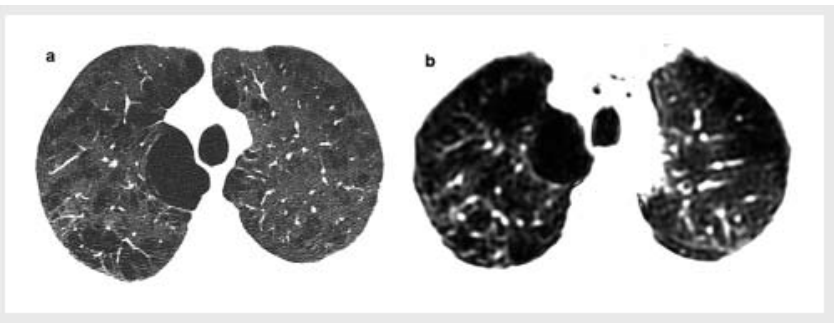

- Fig. 2 Qualitative assessment of pulmonary emphysema in a subject with centrilobular and paraseptal bullae on CT $\mathbf{a}$ and MRI $\mathbf{b}$. The slight discrepancies between the images are due to different breathing positions (CT images were acquired in inspiratory breathhold while acquisition of MR images was gated to the expiratory phase of the respiratory cycle).

- Abb. 2 Qualitative Bewertung eines Lungenemphysems bei einem Patienten mit zentrilobulären und paraseptalen Bullae in der $\mathrm{CT} \mathbf{a}$ und in der MRT $\mathbf{b}$. Die geringen Unterschiede beruhen darauf, dass die CT-Aufnahmen in Inspiration aufgenommen wurden, während die Akquisition der MRT-Aufnahmen auf die Phase der Exspiration getriggert wurde.

LDCT $(r=0.912$ and $p<0.001$ for severity in the emphysema group; $r=0.668$ and $p<0.001$ for severity in the control group; $r=0.843$ and $p<0.001$ for emphysema pattern in the emphysema group; $r=1000$ and $p<0.001$ for emphysema pattern in the control group). - Fig. 2 shows an example of the qualitative assessment of emphysema.

- Table 1 shows the number of morphological emphysema patterns as detected by MRI and LDCT. There were 3 cases in the emphysema group, for which MRI assigned a different emphyse-
- Table 1 Number of different morphological patterns of emphysema as qualitatively assigned by MRI and CT.

- Tab. 1 Anzahl an verschiedenen Emphysemformen wie sie in der MRT und in der CT vergeben wurden.

\begin{tabular}{|l|r|r|}
\hline & MRI & CT \\
\hline centrilobular & 13 & 13 \\
\hline paraseptal & 1 & 0 \\
\hline mixed or advanced destructive & 16 & 17 \\
\hline
\end{tabular}

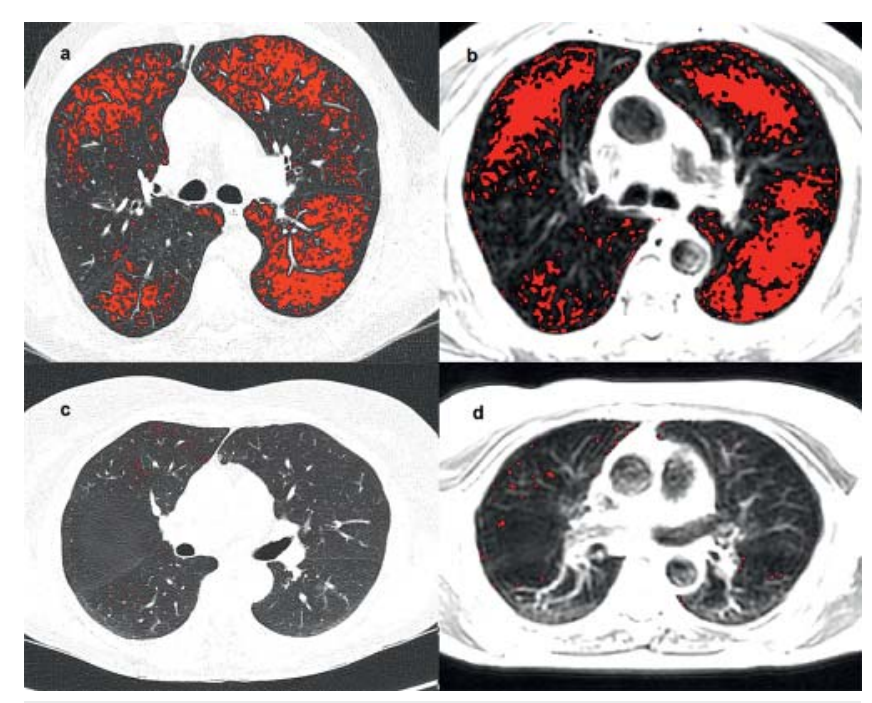

- Fig. 3 Software-based quantitative emphysema analysis in a subject of the emphysema group with an emphysema index of $35.5 \%$ on CT a and $32.5 \%$ on MRI $\mathbf{b}$, and in a control subject with an emphysema index of $0.4 \%$ on CT c and $0.5 \%$ on MRI d.

- Abb. 3 Software-basierte quantitative Emphysemanalyse bei einem Patienten aus der Emphysemgruppe mit einem Emphysemindex von 35,5\% in der CT a und 32,5\% in der MRT $\mathbf{b}$, und bei einer Kontrollperson mit einem Emphysemindex von $0,4 \%$ in der CT c und $0,5 \%$ in der MRT $\mathbf{d}$.

ma pattern than LDCT (centrilobular instead of mixed pattern, paraseptal instead of mixed pattern, and mixed instead of centrilobular pattern in one case each).

The semi-automated software-based segmentation of the lung from the surrounding soft tissue, bones and vessels on MRI was technically successful in all 60 cases. The manual effort for the correction of lung segmentation was less than 3 minutes per case. Representative images of quantitative emphysema analysis are shown in $\mathbf{F i g .} \mathbf{3}$.

The emphysema index was significantly higher in the emphysema group for MRI and LDCT $(p<0.001)(\triangleright$ Table 2$)$ with significant correlation between MRI and LDCT $(r=0.960$ and $p<0.001$ for emphysema group; $r=0.746$ and $p<0.001$ for control group). The Bland-Altman plot and linear regression analysis are shown in - Fig. 4. 

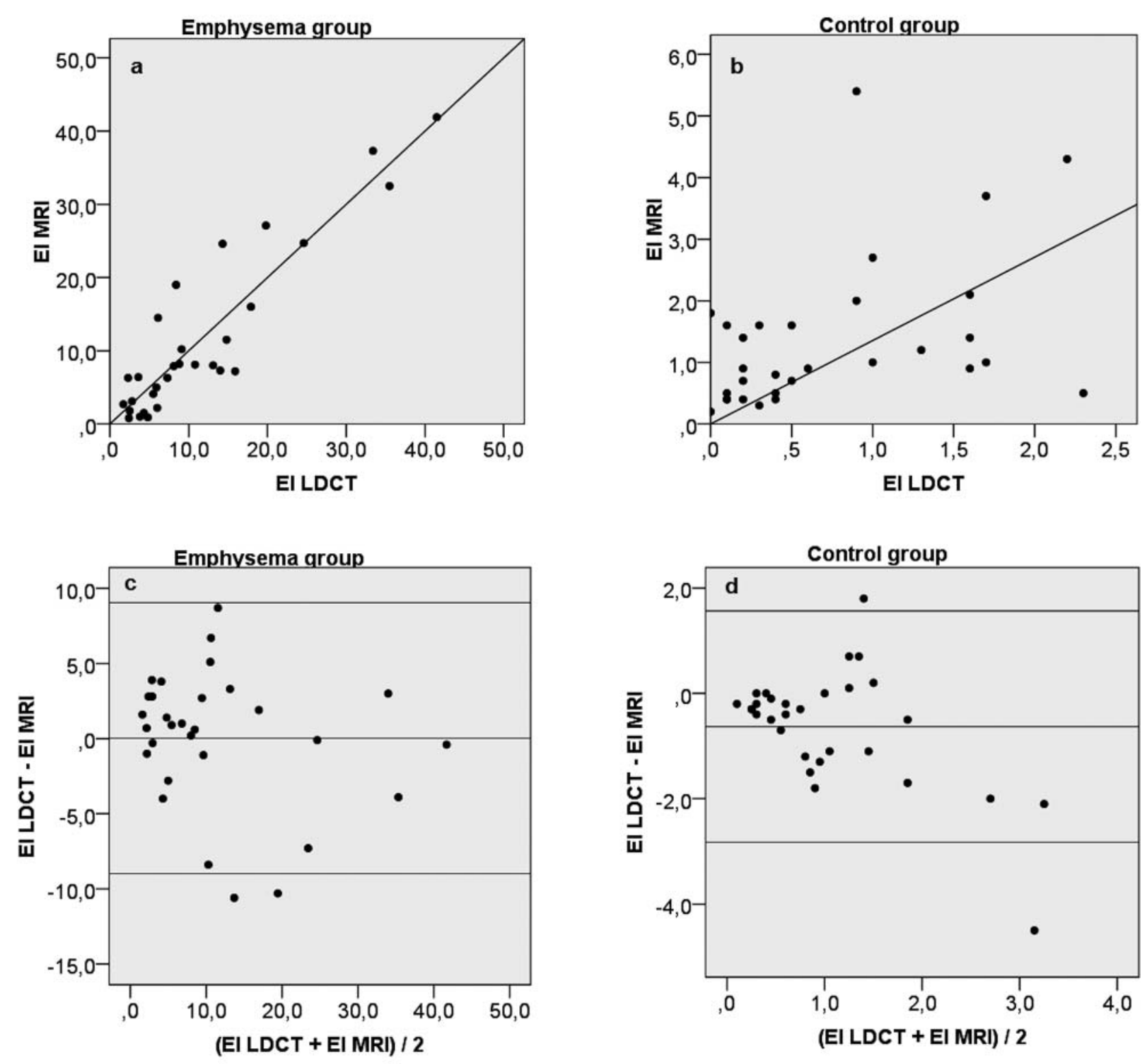

- Fig. 4 Linear regression of emphysema indices (EI) for emphysema group a and control group b, as well as Bland-Altman plot of emphysema indices for emphysema group $\mathbf{c}$ and control group $\mathbf{d}$.

- Abb.4 Lineare Regression der Emphysem-Indices (EI) für die Emphysemgruppe a und die Kontrollgruppe b, sowie Bland-Altman-Diagramm der Emphysem-Indices für die Emphysemgruppe $\mathbf{c}$ und die Kontrollgruppe d.

- Table 2 Mean emphysema index (EI) as calculated on MR and CT images.

- Tab. 2 Durchschnittlicher Emphysem-Index (EI) berechnet in MRT- und CT-Aufnahmen.

\begin{tabular}{|l|c|c|}
\hline & EI MRI & EI LDCT \\
\hline Emphysema group & $11.6 \pm 11.3$ & $11.6 \pm 10.3$ \\
\hline Control group & $1.4 \pm 1.2$ & $0.7 \pm 0.7$ \\
\hline
\end{tabular}

\section{Discussion}

The main finding of this study is that T2-weighted PROPELLER MRI, which has been shown to be suitable for lung imaging [18 - 21], may also be used for the assessment of pulmonary emphysema despite its lower spatial resolution compared to CT. The results are comparable to previously published studies using UTE imaging and functional MRI in subjects with emphysema [10 - 13, 15], while being technically more easy to implement.

The software-based quantitative assessment of pulmonary emphysema on CT images is well established. Regarding normal- 
dose CT with a slice thickness of $1 \mathrm{~mm}$, a threshold of - $950 \mathrm{HU}$ seems to be optimal for CT densitometry analysis of emphysema [4-6, 22]. Yet, in a statement of the Fleischner Society, Lynch et al. pointed out that excessive image noise with a reduced $\mathrm{CT}$ dose can simulate emphysema, particularly on quantitative CT [4]. Moreover, image quality and noise level with simulated $\mathrm{mAs}$ levels below $60 \mathrm{mAs}$ were significantly inferior to images with higher simulated mAs levels in a study by Ley-Zaporozhan et al. [23]. They concluded that imaging dose could be lowered to $60 \mathrm{mAs}$ in thin-slice CT without a diagnostically relevant increase in noise impairing image quality. Hence, the optimal threshold for emphysema quantification with low-dose CT using mAs levels below $30 \mathrm{mAs}$ as in our study has yet to be determined. After testing different thresholds from -910 to $-950 \mathrm{HU}$, we decided to use a midway threshold of $-930 \mathrm{HU}$ in our study, since this value correlated best with the results of the qualitative emphysema analysis (in many cases with a threshold of - $950 \mathrm{HU}$; lucencies that were apparently related to emphysema were not indicated as such by the CT software tool, while a threshold of $-910 \mathrm{HU}$ led to an obvious overestimation in visual analysis). This is in contrast with a study of Gierada et al., who showed that there were no significant differences between normal-dose and LDCT for emphysema analysis [24]. However, the reconstructed slice thickness in their study was $5 \mathrm{~mm}$ and the tube current-exposure time product was $30-60 \mathrm{mAs}$, while slice thickness and radiation dose of LDCT were much lower in our study ( $2 \mathrm{~mm}$ and $25 \mathrm{mAs}$ ). In addition, the absolute CT threshold was not particularly important for this study, since our intention was the correlation with MRI, and not to find the most suitable threshold for densitometry analysis on LDCT.

Based on our study results, pulmonary emphysema may be assessed quantitatively with structural T2-weighted PROPELLER MRI. Still, it should be mentioned that the correlation was excellent when emphysema was present, but a little less valid in subjects without emphysema.

To the best of our knowledge, there is only one study by Roach et al. [13] including software-based emphysema quantification using structural MRI (UTE). However, high-resolution UTE imaging of the lung might not be feasible in the clinical routine, since it is technically demanding and might take up to 20 minutes for image acquisition [12, 13]. In comparison, most clinical MRI scanners should be able to yield a T2-weighted PROPELLER sequence similar to the one being used in our study. Thus, the presented approach may be more transferable to clinical routine. Our study results suggest that T2-weighted PROPELLER MRI may have the potential to be used for the quantification and phenotyping of severe pulmonary emphysema, and subsequently for the identification of progression in follow-up examinations to avoid the radiation exposure of repeated CT scans. At the same time, this approach would allow for the detection of other relevant findings, such as pulmonary nodules or inflammatory changes as previously shown $[10,12,21]$.

Our study has several limitations. First, this is a retrospective study, since the images were not primarily acquired for the analysis of pulmonary emphysema. However, the intention of the present study was to evaluate whether emphysema could be assessed with a conventional T2-weighted PROPELLER sequence that can be easily applied in the clinical routine. Second, the results of emphysema analysis were not correlated with spirometric parameters such as the forced expiratory volume in the first secondforced vital capacity-ratio (FEV1/FVC). This is desirable in future studies. The third limitation is the low sample size of our study population. A fourth limitation is that some LDCT datasets with distinct noise overlay (especially seen in adipose individuals) or extensive atelectasis/infiltrates were excluded from further analysis with MRI, which may have led to a preselection bias. And fifth, subjects with mild emphysema were not part of the analysis. Even though it was not evaluated in this study, we have to assume that the current T2-weighted PROPELLER sequence would probably not be capable of detecting slight emphysematous changes as reliably as severe emphysema due to the much lower spatial resolution compared to LDCT. Still, this did not have a major influence on the visual scoring.

In conclusion, the presence and extent of pulmonary emphysema may be assessed qualitatively and quantitatively using T2-weighted PROPELLER MRI with very good correlation to LDCT according to the present study. However, our study results should be validated in larger prospective studies.

\section{Conflict of Interest}

The authors declare that they have no conflict of interest.

\section{Widmung}

Diese Arbeit ist Herrn Universitäts-Professor Hans H. Schild gewidmet, bei dem wir uns herzlich für die langjährige und stete Unterstützung in allen klinischen und wissenschaftlichen Belangen bedanken möchten.

References

[1] GOLD 2017, Global Strategy for the Diagnosis, Management and Prevention of COPD. Available at: http://goldcopd.org/gold-2017-globalstrategy-diagnosis-management-prevention-copd/. Accessed December 19th, 2017

[2] Mannino DM, Doherty DE, Sonia Buist A. Global Initiative on Obstructive Lung Disease (GOLD) classification of lung disease and mortality: findings from the Atherosclerosis Risk in Communities (ARIC) study. Respir Med 2006; 100: 115-122

[3] Haruna A, Muro S, Nakano Y et al. CT scan findings of emphysema predict mortality in COPD. Chest 2010; 138: 635-640

[4] Lynch DA, Austin JH, Hogg JC et al. CT-Definable Subtypes of Chronic Obstructive Pulmonary Disease: A Statement of the Fleischner Society. Radiology 2015; 277: 192-205

[5] Lynch DA, Al-Qaisi MA. Quantitative computed tomography in chronic obstructive pulmonary disease. J Thorac Imaging 2013; 28: 284-290

[6] Gietema HA, Müller NL, Fauerbach PV et al. Quantifying the extent of emphysema: factors associated with radiologists' estimations and quantitative indices of emphysema severity using the ECLIPSE cohort. Acad Radiol 2011; 18: 661-671

[7] Wild JM, Marshall H, Bock M et al. MRI of the lung (1/3): methods. Insights Imaging 2012; 3: 345-353

[8] Biederer ], Beer M, Hirsch W et al. MRI of the lung (2/3). Why ... when ... how? Insights Imaging 2012; 3 (4): 355-371 
[9] Biederer ], Ohno Y, Hatabu $\mathrm{H}$ et al. Screening for lung cancer: Does MRI have a role? Eur J Radiol 2017; 86: $353-360$

[10] Ley-Zaporozhan J, Ley S, Eberhardt R et al. Visualization of morphological parenchymal changes in emphysema: comparison of different MRI sequences to 3D-HRCT. Eur J Radiol 2010; 73: 43-49

[11] Hoffman EA, Lynch DA, Barr RG et al. Pulmonary CT and MRI phenotypes that help explain chronic pulmonary obstruction disease pathophysiology and outcomes. J Magn Reson Imaging 2016; 43: 544 - 557

[12] Ohno Y, Koyama H, Yoshikawa T et al. Pulmonary high-resolution ultrashort TE MR imaging: Comparison with thin-section standard- and lowdose computed tomography for the assessment of pulmonary parenchyma diseases. J Magn Reson Imaging 2016; 43: 512 - 532

[13] Roach DJ, Crémillieux Y, Serai SD et al. Morphological and quantitative evaluation of emphysema in chronic obstructive pulmonary disease patients: A comparative study of MRI with CT. J Magn Reson Imaging 2016; 44: $1656-1663$

[14] Bauman G, Puderbach M, Deimling M et al. Non-contrast-enhanced perfusion and ventilation assessment of the human lung by means of Fourier decomposition in proton MRI. Magn Reson Med 2009; 62: 656 664

[15] Bauman G, Lützen U, Ullrich M et al. Pulmonary functional imaging: qualitative comparison of Fourier decomposition MR imaging with SPECT/CT in porcine lung. Radiology 2011; 260: 551 - 559

[16] Fain SB, Korosec FR, Holmes JH et al. Functional lung imaging using hyperpolarized gas MRI. J Magn Reson Imaging 2007; 25: 910-923
[17] Qing K, Ruppert K, Jiang Y et al. Regional mapping of gas uptake by blood and tissue in the human lung using hyperpolarized xenon-129 MRI. J Magn Reson Imaging 2014; 39: 346- 359

[18] Serra G, Milito C, Mitrevski M et al. Lung MRI as a possible alternative to CT scan for patients with primary immune deficiencies and increased radiosensitivity. Chest 2011; 140: 1581 -1589

[19] Ciet P, Serra G, Bertolo S et al. Assessment of CF lung disease using motion corrected PROPELLER MRI: a comparison with CT. Eur Radiol 2016; 26: $780-787$

[20] Meier-Schroers M, Kukuk G, Homsi R et al. MRI of the lung using the PROPELLER technique: artifact reduction, better image quality and improved nodule detection. Eur ] Radiol 2016; 85: 707 - 713

[21] Meier-Schroers M, Homsi R, Skowasch D et al. Lung cancer screening with MRI: results of the first screening round. J Cancer Res Clin Oncol 2017. doi:10.1007/s00432-017-2521-4

[22] Wang Z, Gu S, Leader JK et al. Optimal threshold in CT quantification of emphysema. Eur Radiol 2013; 23: 975 - 984

[23] Ley-Zaporozhan J, Ley S, Krummenauer F et al. Low dose multi-detector CT of the chest (iL-EAD Study): visual ranking of different simulated mAs levels. Eur J Radiol 2010; 73: 428-433

[24] Gierada DS, Pilgram TK, Whiting BR et al. Comparison of standard- and low-radiation-dose CT for quantification of emphysema. Am J Roentgenol 2007; 188: $42-47$ 